\title{
Retraction Note to: Individual- and condition-dependent effects on habitat choice and choosiness
}

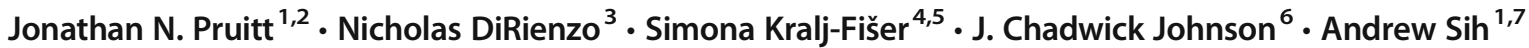

Published online: 11 March 2021

(C) Springer-Verlag GmbH Germany, part of Springer Nature 2021

\section{Retraction Note to: Behav Ecol Sociobiol (2011) 65:1987-1995 https://doi.org/10.1007/s00265-011-1208-0}

This article (Pruitt et al. 2011) has been retracted by the Editors-in-Chief at the request of the authors. After publication, the authors found anomalies in the raw data that were collected. The conclusions presented based on these data are therefore unreliable. Nicholas DiRienzo, Simona Karlj-Fiser, J. Chadwick Johnson, and Andrew Sih agree with this retraction. Jonathan Pruitt has not explicitly stated whether he agrees with this retraction.

The online version of the original article can be found at https://doi.org/ 10.1007/s00265-011-1208-0

Jonathan N. Pruitt

Agelenopsis@gmail.com

1 The Center for Population Biology, University of California, Davis, CA 95616, USA

2 Department of Biological Sciences, University of Pittsburgh, Pittsburgh, PA 15260, USA

3 Animal Behavior Graduate Group, Department of Neurobiology, Physiology, and Behavior, University of California, Davis, CA 95616, USA

4 Biozentrum Grindel, University of Hamburg, Martin-Luther-King Platz 3, 20146 Hamburg, Germany

5 Institute of Biology, Scientific Research Centre, Slovenian Academy of Sciences and Arts, SI 1000 Ljubljana, Slovenia

6 Division of Mathematical and Natural Sciences (2352), Arizona State University, West Thunderbird Rd, Glendale, AZ 85306, USA

7 Department of Environmental Science and Policy, University of California, Davis, CA 95616, USA

\section{Reference}

Pruitt JN, DiRienzo N, Kralj-Fišer S, Johnson JC, Sih A (2011) Individual- and condition-dependent effects on habitat choice and choosiness. Behav Ecol Sociobiol 65:1987-1995. https://doi.org/10. 1007/s00265-011-1208-0

Publisher's note Springer Nature remains neutral with regard to jurisdictional claims in published maps and institutional affiliations. 